RESEARCH GRANTS Social Venture for MSF

THe National Science Foundation has taken a small but potentially important step towards the social sciences by announcing a programme for the support of research "designed to provide information basic to resolving important problems of modern society". The programme was announced by $\mathrm{Dr}$ William D. McElroy, the director of the NSF, over the Christmas holidays. The statement which has been circulated to universities and colleges in the United States explains that the foundation is hoping to encourage in this way interdisciplinary research that will contribute to the understanding of contemporary social problems. The foundation has emphasized, however, that the new programme is not meant to support "social action programs, the widespread application of technological devices or research that would duplicate" programmes supported elsewhere in the federal government. The now venture is known by the acronym IRRPOS, for Intcrdisciplinary Research Relevant to Problems of Our Society. Dr Joel A. Snow, recently of the University of Illinois, has becn appointed acting head of the office, which will have $\$ 6$ million to spend in the current year. The NSF hopes that this amount might be significantly increased in future years.

The foundation explains that in awarding grants, it will be concerned to find projects with long range promise of solving important social problems as well as with scientific merit. It singles out for special mention the problems of poverty, population control, urban environment and the quality of the environment. Student participation is allowed and even encouraged. Plainly the foundation is a little alarmed that the necessary difficulty of defining in advance what prosrammes it will support may encourage investigators to submit woolly proposals, for it asks that applicants should "concentrate on a clearly defined problem". To make sure, there is to be a procedure of prior consultation before formal proposals are designed and, not unnaturally, it seems to be expected that the process of awarding grants will be comparatively protracted. The new departure for the National Science Foundation is very much in tune with the promptings of those who have been urging a more vigorous attack on the scientific aspects of modern social problems. It is also clear, however, that the NSF is acutely aware that too close an involvement with social problems may encourage some of the vagueness which is associated with a good deal of research in the social sciences. 'The success of the new venture will no doubt be determined by its avoidance of this pitfall.

\section{MARS 1973}

\section{Viking Experiments Picked}

Tre National Aeronautics and Space Administration has now published the list of experiments selected for the 1973 Viking project, which will be an attempt at an automatic soft-landing on Mars, and they include an attempt to detect seismic activity. Following NASA practice, the chances of success will be doubled by dispatching two identical spacecraft. Each will detach a landing capsule when it reaches a Mars orbit, while the rest of the package will stay in orbit to map the surface of the planet. Judging by the list of experiments, the landing capsule is going to be the bulkiest part, with eight experiments compared with three on the orbiter. There will also be the usual celestial mechanics experiment which is standard for all planetary probes, for what it involves is simply the reception of radio signals from the spacecraft. The same gocs for the experiment which determines atmospheric properties from the occultation of the radio signal when the probe is eclipsed by Mars.

The orbiting part sounds like a repetition of the two Mariners planned for launch in May 1971, which are to orbit Mars for three months to obtain complete photographic coverage. 'The Viking orbiters will carry television cameras as well as experiments to map the distribution of water in the atmosphere and the variation of temperature on the surface. With the evidence that the pole caps are solid carbon dioxide, it looks as if the water vapour experiment will have a thin time.

Attention will centre on the landing capsules, which have a complement of experiments reminiscent of the old Surveyors but with several extras thrown in. Nobody will be giving much for the chances of the active biology experiment which according to NASA is for the detection of photosynthesis, respiration, metabolism and growth of microorganisms, but it is important to know. Another experiment is to look for organic materials and water in surface material and the atmosphere. Otherwise, the selectors have wisely decided not to devote any more valuable weight to the slim chance of finding life.

\section{RADIO ASTRONOMY \\ JPL. Helps Out}

THE Jet Propulsion Laboratory has announced that some of the facilities of its Deep Space Network are to be made available to qualified radio scientists without charge. Scientists who may be interested, and who will have to provide any special equipment which may be necessary, as well as material with which to ply the recording machines, are invited to apply for further information to Mr Don Spitzmesser, CIT JPL, 238-334, 4800 Oak Greve Drive, Pasadena, California 91103. The Iaboratory will try to select those proposals which seem to be qualified on the grounds of scientific merit, which are likely to make especially good use of the equipment available and which are likely to be compatible with it. A pane] under Professor Jesse Greenstein of the California Institute of Technology will advise on selection.

The Deep-Space Tracking Network is well provided. with equipment. At Goldstone in California, there is a 210 foot paraboloid and a smaller instrument 85 feet across which is the prototype of similar instruments at tracking stations outside the United States. The Jet Propulsion Laboratory explains that the large dish is at present used in the $2.3 \mathrm{GHz}$ range, with zenith temperatures $20 \mathrm{~K}$ and with an aperture efficiency of $0 \cdot 6$. By the middle of 1970 , the large dish should be equipped for the $8 \mathrm{GHz}$ range with a system temperature of $30 \mathrm{~K}$. The intention is that some 5 per cent of the observing time of the large dish should be made available to radio-astronomers. Even this fraction may, however, help repair some of the frustration caused by the shortage of instruments in the past several years. 